\title{
Falco-tentorial meningioma producing irreversible midbrain damage
}

\author{
Amit Agrawal \\ Professor of Neurosurgery, Department of Neurosurgery, Narayna Medical College Hospital, \\ Chinthareddypalem, Nellore, Andhra Pradesh (India)
}

\begin{abstract}
Meningiomas arising from the falcotentorial junction are the rarest subgroup of tentorial menigiomas. Because of the distance from the brain surface and the surrounding deep cerebral veins these lesions are difficult and dangerous to treat surgically. A 45-year-old female presented with the history of progressive headache, disorientation, unsteadiness, and urinary incontinence for over 6 months. The patient developed difficulty in swallowing, and weakness of all four limbs for the last 7 days. CT scan brain plain and contrast showed a large well defined, homogenously enhancing mass lesion in the peineal region with compression of the upper brain stem and obstructive hydrocephalus. Inspite of the good surgical decompression the patient did not do well. As described in the literature, the compression of the midbrain can cause severe respiratory disturbances with fatal outcome; probably the similar mechanism resulted in poor outcome in present case. As we noticed the diffuse hypodensity in midbrain on CT scan, similar findings have been described in literature in cases of transtentorial herniation
\end{abstract}

with poorer outcome.

Key words: Falcotentorial meningioma, midbrain, transtentorial herniation

\section{Introduction}

Meningiomas arising from the falcotentorial junction are the rarest subgroup of tentorial menigiomas. (1-5) Because of the distance from the brain surface and the surrounding deep cerebral veins these lesions are difficult and dangerous to treat surgically. (6-9)

\section{Case report}

A 45-year-old female presented with the history of progressive headache, disorientation, unsteadiness, and urinary incontinence for over 6 months. The patient developed difficulty in swallowing, and weakness of all four limbs for the last 7 days. She had multiple episodes of vomiting and was in altered sensorium for last three days. There was no history of fever or trauma. On neurological examination she was unconscious (GCS-E2V1, M3). Pupils were bilateral equal and reacting to light. Fundus 
showed bilateral papilloedema. Extra ocular movements were restricted in all directions. She had spastic quadriparesis. Her general and systemic examination was unremarkable. Blood investigations were normal except low hemoglobin (8 gm \%). CT scan brain plain and contrast showed a large well defined, homogenously enhancing mass lesion in the peineal region with compression of the upper brain stem and obstructive hydrocephalus (Figures 1 and 2).

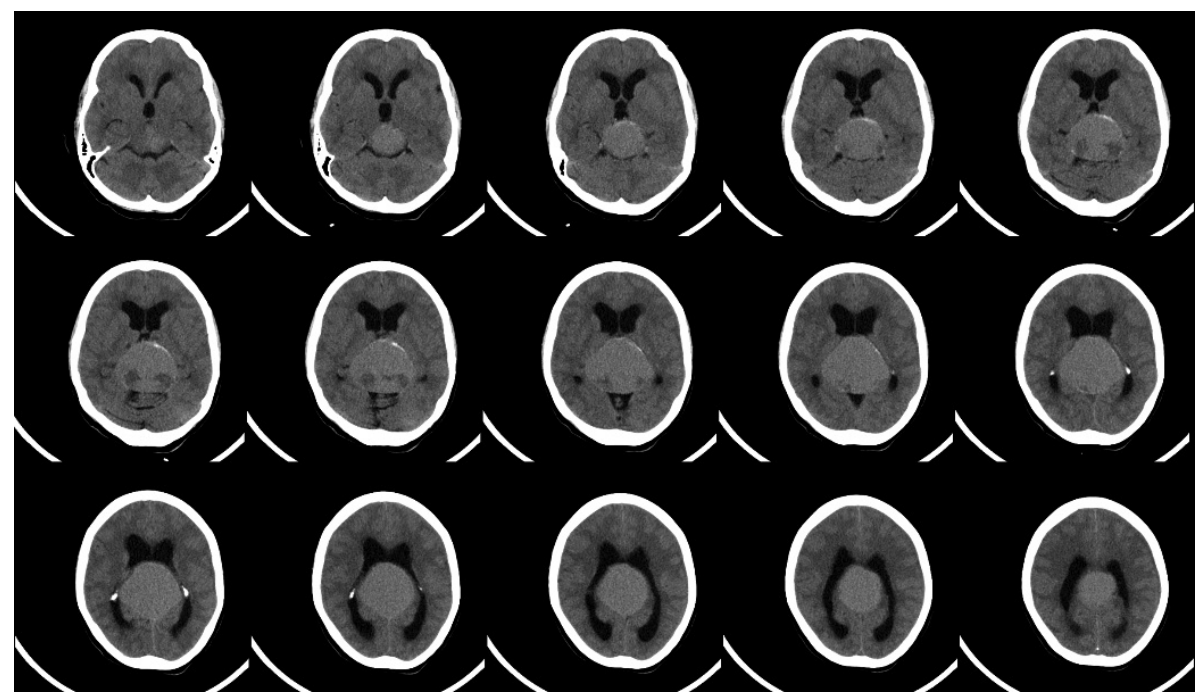

Figure 1 - Plain CT scan brain showing a large showing mass lesion in the pineal region with hydrocephalus

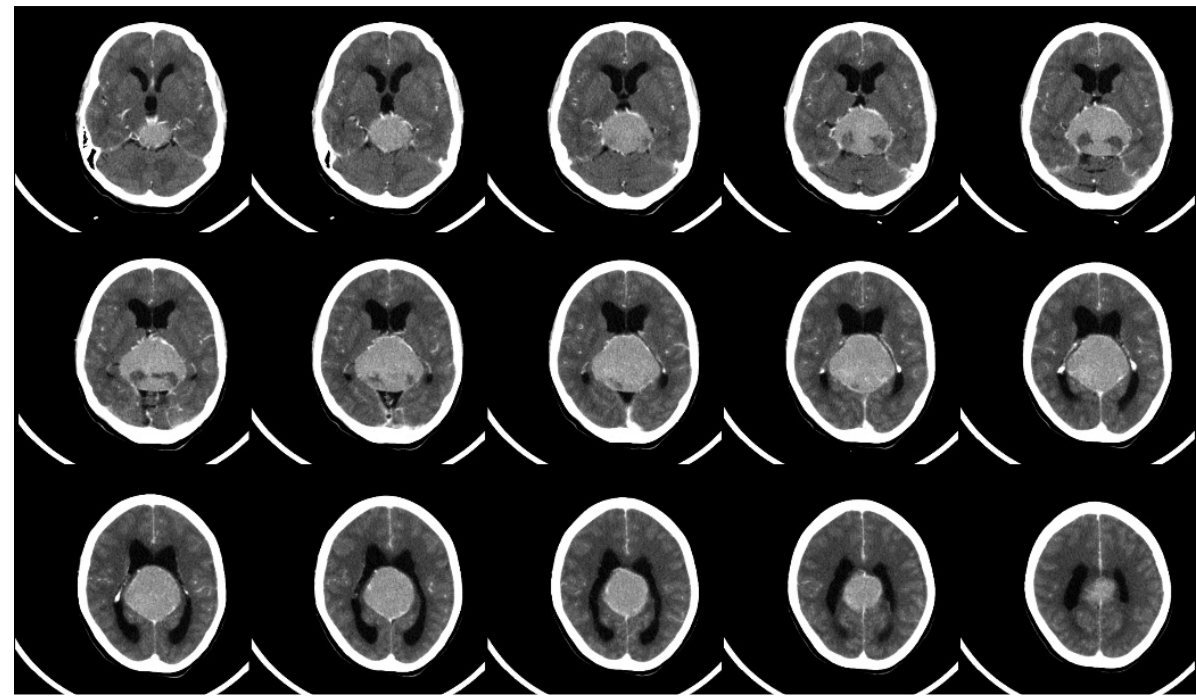

Figure 2 - Contrast CT scan brain showing the homogenous enhancement after contrast administration 


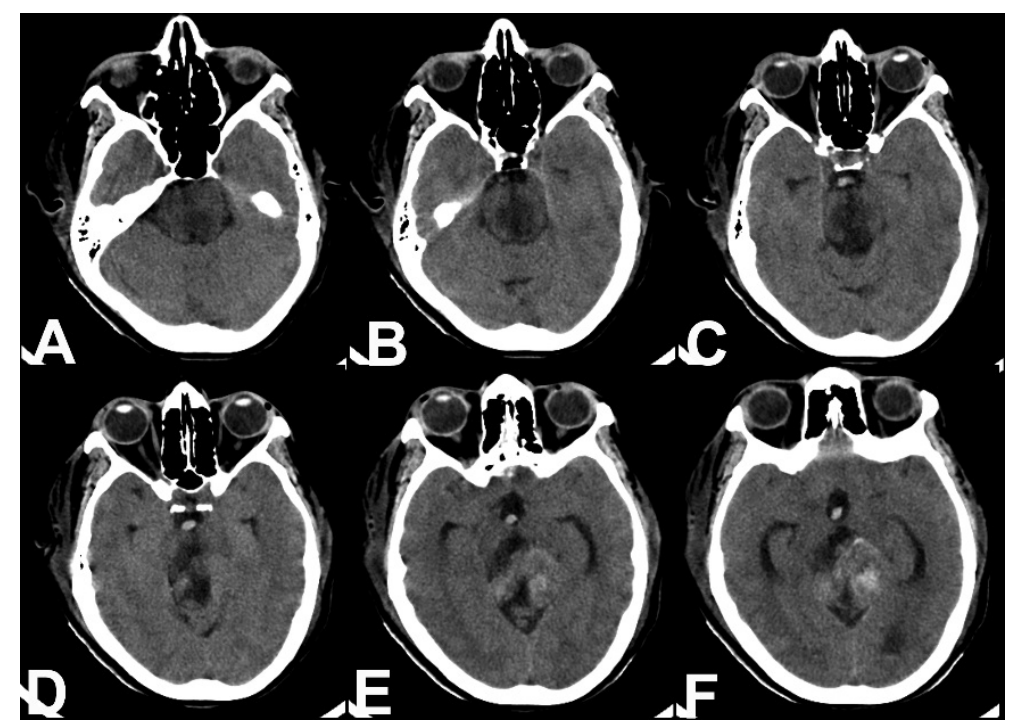

Figure 3 - Post-operative follow up CT scan showing diffuse hypodensity involving the midbrain

The patient was operated using a right interhemisheric parieto-occipital approach consisted of a unilateral parieto-occipital craniotomy exposing the ipsilateral torcula, superior sagittal sinus, transverse sinus and the occipital lobe. During surgery the major part of the tumor was found to be attached to the falco-tentorial junction and a near total excision of the lesion was performed. Followed surgery initially patient improved in her sensorium (opening eyes to call), but there was no improvement in her other neurological parameters. At day two she again deteriorated in her sensorium and a repeat CT scan showed increase in the hydrocephalus and diffuse hypodensity in the midbrain (Figure 3). The patient underwent right ventriculoperitoneal shunt, however she did not improve and continued to deteriorate. She expired on day six. Histological examination demonstrated a fibroblastic type of meningioma.

\section{Discussion}

The ideal surgical approach should allow prompt and gross total removal of falcotentorial meningiomas with minimum brain retraction and at the same time safeguard the galenic system and neighboring vital structures. $(5,10)$ Although total total tumour excision is the goal, however it may not be possible in all the cases. $(2,10-12)$ To achieve the total excision many operative approaches have been described and include transcallosal, occipital transtentorial, infratentorial supracerebellar approaches and sitting, prone or Concorde positions. (11) We used the parieto-occipital route to access the lesion in the present case, which has been described as the shortest way to reach epiphysis and falco-tentorial notch. $(11,13)$ Uneventful postoperative courses without neurological deficits and an excellent outcome have been reported after complete removal of 
the tumor. (1-5) However, the inferior extension of the tumor can compress the deep veins and the brainstem, although occlusion of deep veins may not significantly influence the outcome. (12) As described in the literature, the compression of the midbrain can cause severe respiratory disturbances with fatal outcome, (14) probably the similar mechanism resulted in poor outcome in present case. As we noticed the diffuse hypodensity in midbrain on CT scan, similar findings have been described in literature in cases of transtentorial herniation with poorer outcome. (15)

\section{Correspondence}

Dr. Amit Agrawal

Professor of Neurosurgery

Department of Neurosurgery

Narayana Medical College Hospital

Chinthareddypalem

Nellore-524003

Andhra Pradesh (India)

Email-dramitagrawal@gmail.com

dramit_in@yahoo.com

Mobile - +91-8096410032

\section{References}

1.Asari S, Maeshiro T, Tomita S, Kawauchi M, Yabuno N, Kinugasa K, Ohmoto T. Meningiomas arising from the falcotentorial junction. Clinical features, neuroimaging studies, and surgical treatment. J Neurosurg. 1995;82(5):726-38.

2.Okami N, Kawamata T, Hori T, Takakura K. Surgical treatment of falcotentorial meningioma. J Clin Neurosci. 2001;8 Suppl 1:15-8.

3.Quiñones-Hinojosa A, Chang EF, Chaichana KL, McDermott MW. Surgical considerations in the management of falcotentorial meningiomas: advantages of the bilateral occipital transtentorial/transfalcine craniotomy for large tumors. Neurosurgery. 2009;64(5 Suppl 2):260-8.
4.Quinones-Hinojosa A, Chang EF, McDermott MW. Falcotentorial meningiomas: clinical, neuroimaging, and surgical features in six patients. Neurosurg Focus. 2003 ;14(6):e11.

5.Majchrzak K, Tymowski M. Surgical treatment of the tentorial and falco-tentorial junction meningiomas. Minim Invasive Neurosurg. 2009;52(2):93-7.

6.Matsuda Y, Inagawa T. Surgical removal of pineal region meningioma--three case reports. Neurol Med Chir (Tokyo). 1995;35(8):594-7.

7.Nakayama K, Miyasaka Y, Ohwada T, Yada K. [Meningioma in the pineal region--report of a case and review of the literature (author's transl)]Neurol Med Chir (Tokyo). 1980;20(3):265-71. (in Japanese)

8.Suzuki S, Mizoi K, Kato S, Suzuki J: A successful removal of huge confluence meningioma. No Shinkei Geka 1988 ;16: 289-294. (in Japanese)

9.Toyota A, Takahashi A, Yoshida Y, Murakami T, Saiki I, Kanaya H: Meningioma of pineal region. No Shinkei Geka $1990 ; 18: 745-749$. (in Japanese)

10.Raco A, Agrillo A, Ruggeri A, Gagliardi FM, Cantore G. Surgical options in the management of falcotentorial meningiomas: report of 13 cases. Surg Neurol. 2004;61(2):157-64.

11.Brotchi J, Raftopoulos C, Levivier M, Dewitte O, Pirotte B, Vandesteene A, Baleriaux D, Noterman J. [Lesions of the pineal and tentorial region. Occipitoparietal approach in three-quarter prone position with infrasagittal craniotomy][Article in French] Neurochirurgie. 1991;37(6):410-5.

12.Goto T, Ohata K, Morino M, Takami T, Tsuyuguchi N, Nishio A, Hara M. Falcotentorial meningioma: surgical outcome in 14 patients. J Neurosurg. 2006;104(1):47-53.

13.Misu N, Hirota T, Tohyama K. [Meningioma of the falco-tentorial junction developing into the pineal region. Report of two cases][Article in Japanese] Neurol Med Chir (Tokyo). 1987;27(4):313-8.

14.Topsakal C, Kaplan M, Erol F, Cetin H, Ozercan I. Unusual arachnoid cyst of the quadrigeminal cistern in an adult presenting with apneic spells and normal pressure hydrocephalus--case report. Neurol Med Chir (Tokyo). 2002;42(1):44-50.

15.Hattori T, Yamakawa H, Kobayashi H, Niikawa S, Ohkuma A. Computed tomographic features of central descending transtentorial herniation--case report. Neurol Med Chir (Tokyo). 1990;30(1):51-3. 